11,01

\title{
Образование дендритной структуры в кристаллах NiFeGaCo при выращивании способом Степанова
}

\author{
() Ю.Г. Носов, В.М. Крымов, М.Г. Васильев, А.В. Чикиряка, В.И. Николаев \\ Физико-технический институт им. А.Ф. Иоффре, \\ Санкт-Петербург Россия \\ E-mail: v.krymov@mail.ioffe.ru
}

Поступила в Редакцию 13 июля 2021 г.

В окончательной редакции 13 июля 2021 г.

Принята к публикации 15 июля 2021 г.

\begin{abstract}
Способом Степанова выращены кристаллы сплава NiFeGaCo. Обнаружено, что структурное совершенство кристаллов нарушается образованием дендритов, которые распределены неоднородно как по длине, так и по поперечному сечению кристаллов. Найден эффект блокировки дендритами развития мартенситной фазы, возникающей при охлаждении образцов до температуры перехода кристалла в мартенситное состояние. Изучен элементный состав дендритных образований и показано, что содержание железа в дендрите примерно на 30\% больше, а содержание галлия на 40\% меньше, чем в матрице. На основе моделирования процессов теплообмена в реальной ростовой зоне с учетом проведенных опытов получены рекомендации для подавления образования дендритов.
\end{abstract}

Ключевые слова: дендритная структура, сплавы с памятью формы, способ Степанова.

DOI: 10.21883/FTT.2021.12.51680.167

\section{1. Введение}

В последние десятилетия ферромагнитные никелевые сплавы Гейслера с эффектом памяти формы (ЭПФ) и, в частности, $\mathrm{NiFeGaCo} \mathrm{интенсивно} \mathrm{изучаются} \mathrm{многими}$ исследователями [1-5]. Эти кристаллы интересны возможностью получения больших обратимых магнитоиндуцированных деформаций, сверхупругости (СУ), и эффектом высокоскоростного восстановления деформации памяти формы (ВВДПФ).

Большинство кристаллов $\mathrm{NiFeGaCo} \mathrm{выращены} \mathrm{для}$ исследовательских целей методом Бриджмена [6]. Если рассматривать эту технологию с точки зрения дальнейшего практического применения, то очевидно, что небольшие размеры производимых по ней образцов окажутся недостаточными для большинства конструкций приводов [7]. Следующим логическим этапом исследований, на наш взгляд, должно стать развитие технологии получения подобных кристаллов большой длины и различного заданного сечения, что расширит конструкторские возможности для создания устройств на основе эффектов ЭПФ, СУ и ВСДПФ. Примеры создания устройств на основе профилированных кристаллов CuAlNi с ЭПФ, полученных способом Степанова, продемонстрированы в [8,9]. Ранее нами было показано, что монокристаллы $\mathrm{NiFeGaCo} \mathrm{могут} \mathrm{быть}$ выращены из расплава промышленными методами, например, Чохральского и Степанова, которые позволяют получать высококачественные кристаллы кремния [10] и сапфира [11]. К настоящему времени, в рамках способа Степанова нами получены кристаллы, из которых можно изготовить образцы, сравнимые с теми, что вырезаются из слитков, выращенных методом Бриджмена [12-15].

Однако полноценной реализации функциональных возможностей кристаллов $\mathrm{NiFeGaCo} \mathrm{препятствует} \mathrm{про-}$ блема неоднородности состава и структуры выращенных кристаллов. В частности, мы столкнулись с образованием при выращивании кристаллов дендритов в матрице монокристалла.

Надо заметить, что образование дендритной структуры - достаточно распространенное явление при кристаллизации металлических сплавов на основе железа и никеля [16-21]. Дендриты - это структурный дефект характерной скелетной формы, состоящий из центральной ветви (ось первого порядка) и перпендикулярных ей боковых ветвей. Дендритная структура формируется непосредственно на фронте кристаллизации и далее сохраняется независимо от последующих термообработок, таких как высокотемпературный отжиг и закалка [22].

Цель настоящей работы - исследование причин образования дендритной структуры в кристаллах сплава $\mathrm{Ni}_{49} \mathrm{Fe}_{18} \mathrm{Ga}_{27} \mathrm{Co}_{6}$ при их выращивании и ее влияния на функциональные свойства кристаллов, оптимизация режимов кристаллизации для подавления образования дендритов.

\section{2. Эксперимент}

\section{1. Рост кристаллов методом Степанова}

Методом Степанова из расплава на кристаллографически ориентированную в направлении [100] затравку выращивались кристаллы состава $\mathrm{Ni}_{49} \mathrm{Fe}_{18} \mathrm{Ga}_{27} \mathrm{Co}_{6}$ в ви- 



Рис. 1. Схема тепловой зоны $(a)$ и фотография кристалла во время роста $(b): 1-$ кристалл, $2-$ расплав, $3-$ тигель, 4 - теплоизоляция, 5 - индуктор, 6 - формообразователь.

де цилиндрических стержней, диаметр которых задавался формообразователем. Выращивание проводилось в атмосфере аргона из алундового тигля на установке с индукционным нагревом со скоростью вытягивания $1 \mathrm{~mm} / \mathrm{min}$ в атмосфере аргона. Были выращены кристаллы длиной до $250 \mathrm{~mm}$ и диаметром $6 \mathrm{~mm}$. Схема тепловой зоны и фотография кристалла в процессе выращивания показаны на рис. 1.

\section{2. Определение температуры мартенситных переходов}

Для точного определения температуры перехода аустенита в мартенсит $M_{S}$ образец в форме шайбы с полированной поверхностью помещался в термостат. Охлаждение осуществлялось с очень низкой скоростью: $\sim 0.04 \mathrm{~K} / \mathrm{min}$. За полированной торцевой поверхностью образца проводились наблюдение и фотосьемка. Температура начала мартенситного перехода определялась по появлению первых кристаллов мартенсита на торцевой поверхности. При данных условиях мартенситная структура в кристалле образуется и развивается в интервале температур 9.5-9.0 ${ }^{\circ} \mathrm{C}$. Время от появления первых иголок мартенсита до их распространения на все сечение составляло примерно 18 мин. Обратный переход мартенсит - аустенит происходил при нагревании до $A_{s} \approx 15-16^{\circ} \mathrm{C}$. Температуры фазового перехода определялись на кристаллах $\mathrm{Ni}_{49} \mathrm{Fe}_{18} \mathrm{Ga}_{27} \mathrm{Co}_{6}$, вырезанных из областей без дендритов. Дальнейшее исследование проводилось на выращенных (as grown) кристаллах без какой-либо дополнительной термообработки.

\section{3. Изучение дефектной структуры кристалла}

Структура кристалла изучалась на трех шайбах, вырезанных из выращенного кристалла на расстояниях 15 , 100 и $160 \mathrm{~mm}$ от затравки. Для выявления дендритной структуры эти образцы полировались и химически травились в растворе из трех частей азотной кислоты и одной части соляной. Детали структуры изучались с помощью оптического микроскопа Carl Zeiss Jena Amplival и сканирующего электронного микроскопа Phenom PROX.

На рис. 2, а представлена фотография сечения в $15 \mathrm{~mm}$ от затравки. Видно, что дендриты распределяются по сечению неравномерно: в центральной части плотность дендритов $\mathrm{N}$ меньше, на краях существенно больше. В центральной области кристалла, внутри квадрата $2 \times 2 \mathrm{~mm}$, величина $N$ составляет $10-15$ дендритов на $\mathrm{mm}^{2}$. Для области вблизи края кристалла можно дать только оценку величины $N \approx 50$ дендритов на $\mathrm{mm}^{2}$. Размеры дендритов изменяются в широких пределах: от сотых долей $\mathrm{mm}$ до 0.5-1 mm. Отметим, что все фотографии на рис. 2 (верхний ряд) сделаны при комнатной температуре, когда кристалл находится в аустенитном состоянии.

На рис. 2, $b$ дан вид поверхности кристалла на расстоянии $100 \mathrm{~mm}$ от затравки. Общее число дендритов в этом сечении примерно в два раза меньше, чем в сечении на рис. 1, $a$. Распределение дендритов существенно неравномерное: верхняя часть сечения содержит наибольшее количество дендритов. На рис. 2, с дана картина сечения на расстоянии $160 \mathrm{~mm}$ от затравки. В данном сечении избирательное травление показало полное отсутствие дендритов. 



\section{$e$}
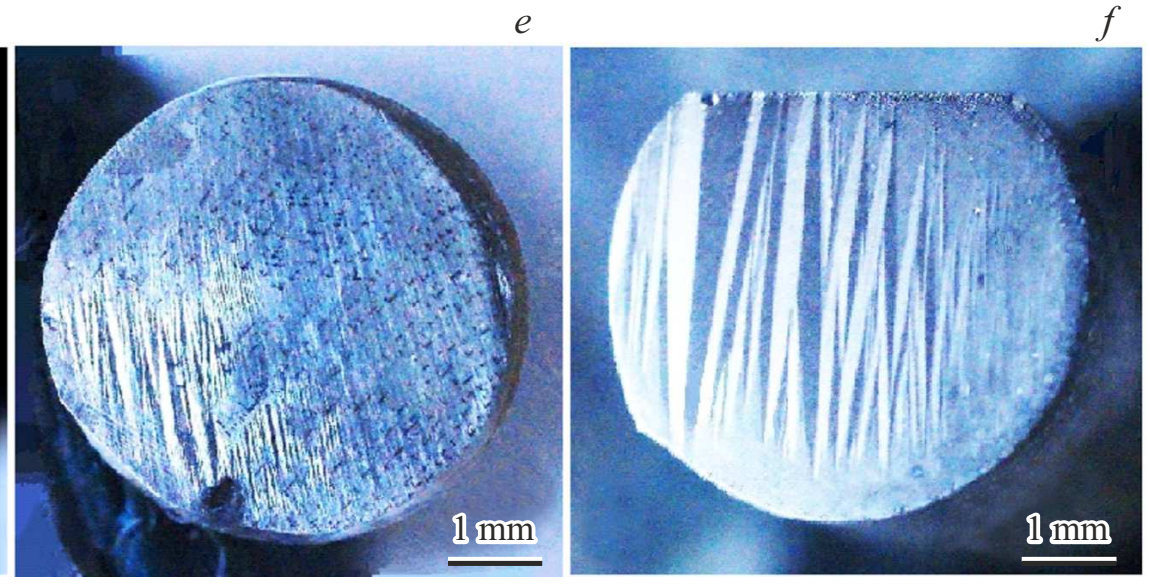

Рис. 2. Фотографии шлифов поперечного сечения кристалла $\mathrm{Ni}_{49} \mathrm{Fe}_{18} \mathrm{Ga}_{27} \mathrm{Co}_{6}$ на расстоянии $15 \mathrm{~mm}(a$ и $d)$, $100 \mathrm{~mm}(b$ и $e$ ) и $160 \mathrm{~mm}(c$ и $f$ ) от затравки. Верхний ряд фотографий - при комнатной температуре (аустенитная фаза), нижний - при охлаждении ниже точки перехода в мартенситное состояние.

Эти данные показывают, что дефектная структура кристалла неоднородна как по сечению, так и по длине слитка. Максимальная концентрация дендритов наблюдалась в начальной части кристалла, ближе к затравке, далее она постепенно снижалась и на расстоянии около $160 \mathrm{~mm}$ от затравки дендриты полностью отсутствовали.

Для исследования структуры образцов при мартенситном переходе все три образца были охлаждены ниже температуры $M_{S}$. При этом на первом образце наблюдалась только исходная дендритная картина (рис. 2,d) и характерные иглы мартенситных кристаллов не проявились. На втором образце (100 mm от затравки) видны одновременно и дендриты, и мартенситные иглы, причем наибольшее число мартенситных игл находится в нижней, свободной от дендритов части сечения (рис. 2,e). И, наконец, на третьем образце, в котором дендриты полностью отсутствовали, видим большие кристаллы мартенсита по всему сечению (рис. $2, f$ ).

Таким образом при охлаждении кристалла ниже температуры $M_{S}$ мартенситные кристаллы появлялись только в тех участках поверхности, где отсутствовали дендриты.

\section{4. Мартенситный переход в кристалле с дендритами}

Охлаждая кристалл, не содержащий дендриты, обычно можно наблюдать следующую картину развития мартенсита. При достижении температуры $M_{S}$ на краю кристалла появлялись мартенситные иглы, которые быстро заполняли все сечение кристалла. Другая картина наблюдается, если кристалл содержит дендриты. В этом случае образование мартенситных кристаллов, дойдя до группы дендритов или до одного большого дендрита, останавливается и через дендриты дальше не продвигается. Пример остановки мартенситных игл перед единичными дендритами приведен на рис. 3.

На этих фотографиях показаны два больших дендрита в сечении кристалла $\mathrm{Ni}_{49} \mathrm{Fe}_{18} \mathrm{Ga}_{27} \mathrm{Co}_{6}$ при комнатной температуре (рис. 3,a) и те же два дендрита в окружении мартенситных игл при охлаждении кристалла до 


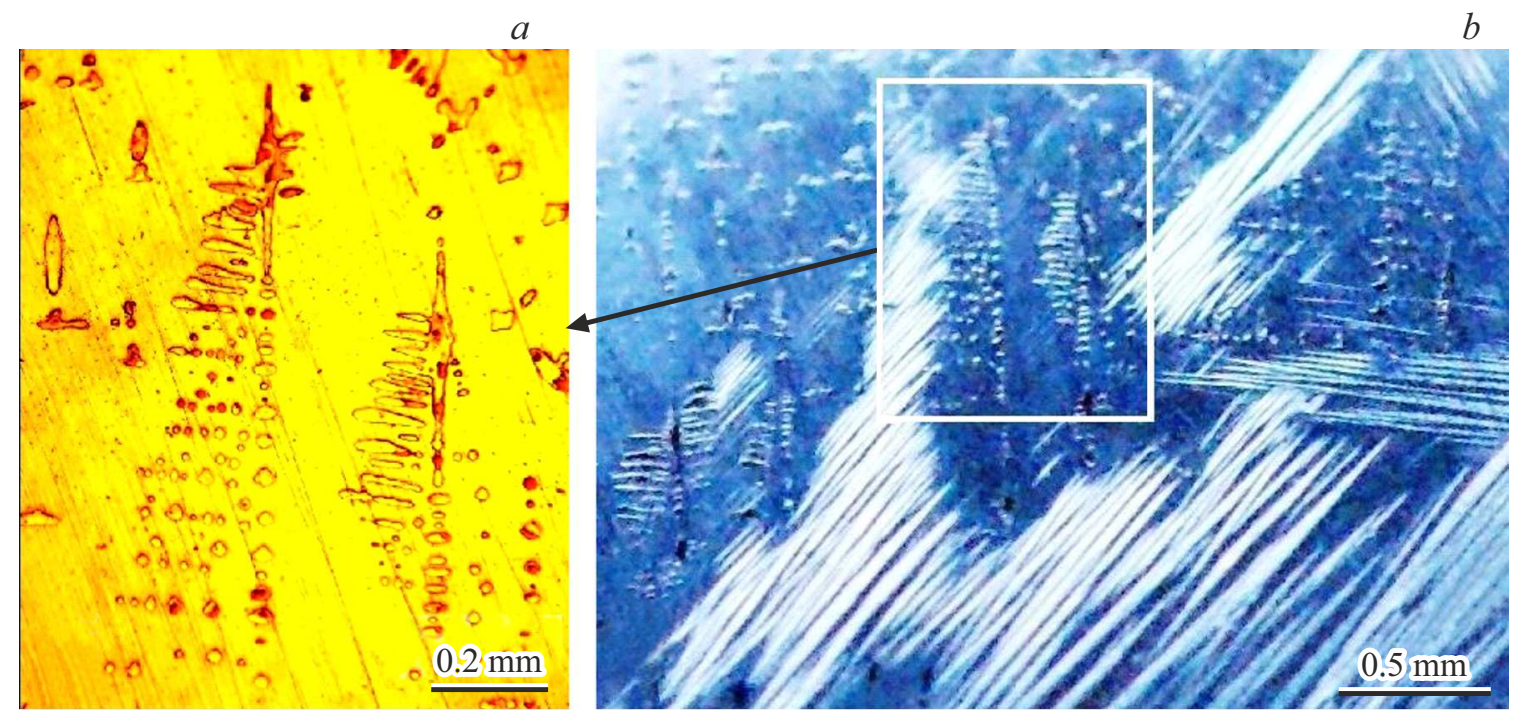

Рис. 3. Фотографии участка сечения кристалла $\mathrm{Ni}_{49} \mathrm{Fe}_{18} \mathrm{Ga}_{27} \mathrm{Co}_{6}$ с характерными дендритами: (a) при комнатной температуре в аустенитном состоянии, $(b)$ тот же образец охлажден до точки начала перехода из аустенита в мартенсит $M_{S}$. В рамке на рис. $3, b$ показан тот же участок поверхности кристалла, что и на рис. $3, a$.

температуры $M_{S}$ (рис. 3, $b$ ). Видно, что мартенситные иглы, подходящие к дендритам с разных направлений, не могут пройти сквозь них. То есть, дендриты являются стопорами при распространении мартенситной фазы в кристаллах.

\section{5. Элементный состав дендритов}

Элементный состав дендритов и областей между ними определялся на сканирующем электронном микроскопе Phenom PROX со встроенной системой энергодисперсионной спектроскопии (ЭДС). Диаметр электронного пучка облучения составлял $\sim 3 \mu \mathrm{m}$. Результаты измерений, приведенные в табл. 1, показали, что по длине кристалла без учета дендритов состав изменяется незначительно и соответствует исходному составу $\mathrm{Ni}_{49} \mathrm{Fe}_{18} \mathrm{Ga}_{27} \mathrm{Co}_{6}$.

Более точные измерения состава в области дендритов показали, что элементный состав тела дендрита отличается от состава окружающей матрицы и всегда в дендрите содержание железа больше, а галлия меньше, чем вне его. На рис. 4 приведен пример измерения элементного состава в дендрите и вблизи него. Видно, что содержание железа в дендрите приблизительно на $30 \%$ больше, а содержание галлия приблизительно на 40\% меньше, чем в областях, примыкающих к дендриту. Содержание никеля и кобальта не показывает значимого скачка на границе дендритов.

\section{3. Моделирование процесса выращивания}

В чем причина найденной структурной неоднородности распределения плотности дендритов по длине кри-

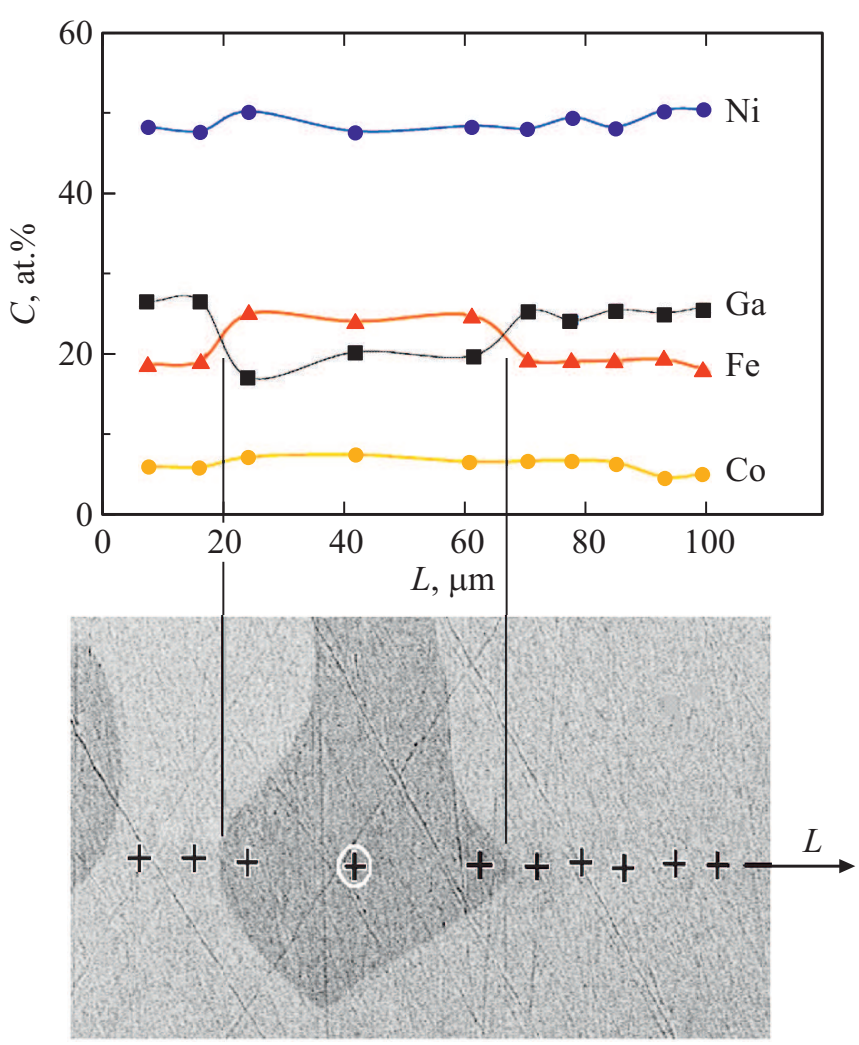

Рис. 4. Распределение элементного состава в области дендрита.

сталла? Поскольку известно, что дендриты образуются непосредственно на фронте кристаллизации, то эта неоднородность может быть обусловлена либо изменением химического состава расплава, либо изменением тепло- 
Таблица 1. Элементный состав кристаллов на разных расстояниях от затравки

\begin{tabular}{c|c|c|c}
\hline \multirow{2}{*}{ Элемент } & \multicolumn{3}{|c}{ Содержание, ат.\% } \\
\cline { 2 - 4 } & $15 \mathrm{~mm}$ от затравки & $100 \mathrm{~mm}$ от затравки & 160 тm от затравки \\
\hline $\mathrm{Ni}$ & 47.4 & 49.0 & 49.1 \\
\hline $\mathrm{Fe}$ & 18.8 & 19.1 & 19.6 \\
\hline $\mathrm{Ga}$ & 27.4 & 25.5 & 24.8 \\
\hline $\mathrm{Co}$ & 6.4 & 6.4 & 6.5
\end{tabular}

вых условий в процессе роста. Первая причина маловероятна, поскольку прямыми измерениями (табл. 1) было показано, что состав меняется незначительно. Наиболее вероятна вторая причина. Поскольку экспериментальные измерения температурных распределений в зоне выращивания достаточно сложны и трудоемки, было привлечено математическое моделирование процессов тепло- и массообмена в реальной тепловой зоне. Оно позволило исследовать влияния параметров роста и конфигурации тепловой зоны на гидродинамику расплава и температурное распределение в растущем кристалле. Этим методом можно также оптимизировать тепловую зону для подавления дендритного роста, выращивания кристаллов различного сечения и достижения максимальной производительности процесса.

Моделирование было выполнено с помощью пакета программ BasicCGSim для реальной тепловой зоны с индукционным нагревом. Расчеты сделаны для случая выращивания кристалла диаметром $6 \mathrm{~mm}$ методом Степанова с использованием формообразующей пластины с отверстием. Скорость роста составляла $60 \mathrm{~mm} / \mathrm{h}$ для базового расчетного варианта. Температура кристаллизации бралась равной $1600 \mathrm{~K}$. Были рассчитаны распределения температур в расплаве, кристалле, а также гидродинамика течения расплава в тигле для последовательных стадий роста при длине кристалла 50, 100 и $160 \mathrm{~mm}$. На рис. 5 показаны картины изотерм и линии течения расплава при длине кристалла $160 \mathrm{~mm}$. Видно, что расплав в тигле активно перемешивается,



Рис. 5. Картина изотермических линий с интервалом $1 \mathrm{~K}$ (справа) и линий тока расплава (слева) при выращивании кристалла методом Степанова. 1 - расплав, 2 - формообразователь, 3 - кристалл.

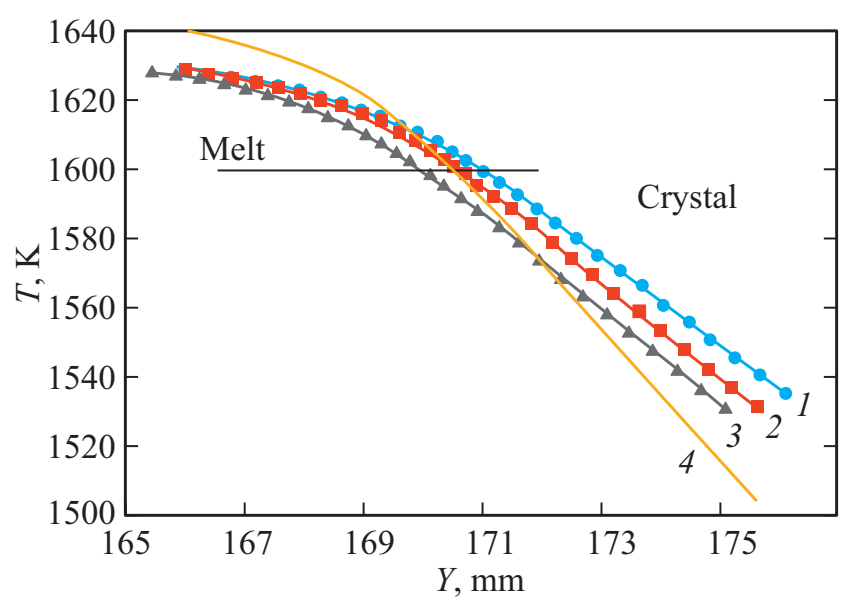

Рис. 6. Распределение температуры вблизи фронта кристаллизации в расплаве и по оси кристалла при выращивании методом Степанова на разных стадиях роста: 1,2 и 3 кристаллы, достигшие длины 50, 100 и $160 \mathrm{~mm}, 4$ - расчет для длины кристалла $100 \mathrm{~mm}$ в тепловой зоне без верхней крышки. Температура кристаллизации $1600 \mathrm{~K}$ отмечена горизонтальной линией.

перемещаясь по спирали от горячих стенок тигля вверх и опускается вниз в центре тигля. На рис. 6 показано распределение температуры по оси выращивания при длине кристалла 50, 100 и $160 \mathrm{~mm}$. Проведенные модельные расчеты показали слабое влияние изменения скорости вытягивания в диапазоне от 10 до $240 \mathrm{~mm} / \mathrm{h}$ на распределение температуры. Нужно отметить, что с помощью моделирования удалось определить такой важный параметр процесса кристаллизации, как градиент температуры на фронте. Экспериментально это сделать очень сложно. Расчеты показывают, что с увеличением длины кристалла градиент температуры в расплаве у фронта кристаллизации растет с $6.9 \mathrm{~K} / \mathrm{mm}$ до $9.7 \mathrm{~K} / \mathrm{mm}$.

\section{4. Обсуждение}

\section{1. Анализ образования дендритной структуры}

Таким образом, наблюдается корреляция между увеличением градиента температуры в расплаве у фронта 
Таблица 2. Соотношение параметра кристаллизации $G_{L} / V$ $\left(G_{L}\right.$ - температурный градиент, $V$ - скорость роста) и дендритной структуры в сплавах

\begin{tabular}{c|c|c|c|c}
\hline$G_{L}, \mathrm{~K} / \mathrm{mm}$ & $V, \mathrm{~mm} / \mathrm{s}$ & $G_{L} / V, \mathrm{Ks} / \mathrm{mm}^{2}$ & Дендриты & Ссылка \\
\hline 80 & 0.015 & 5333 & Нет & {$[18]$} \\
\hline 80 & 0.15 & 533 & Есть & {$[18]$} \\
\hline $10-12$ & 0.0017 & $100-120$ & Нет & {$[24]$} \\
\hline $10-12$ & 0.005 & $30-40$ & Есть & {$[24]$} \\
\hline 10.3 & 0.017 & 606 & Нет & Наши данные \\
\hline 9 & 0.017 & 529 & Есть & Наши данные
\end{tabular}

и исчезновением образования дендритов. Это соответствует классическим представлениям об образовании дендритной структуры при концентрационном переохлаждении расплава. Согласно [23], критерием перехода от ячеистого и дендритного роста к нормальному (планарному) является увеличение параметра $G_{L} / V$, где $G_{L}$ - градиент температуры в расплаве у фронта кристаллизации, а $V$ - скорость выращивания. Увеличение градиента температуры приводит к уменьшению высоты жидко-твердой зоны у фронта кристаллизации, в которой непосредственно формируется дендритная структура. С другой стороны, увеличение скорости выращивания приводит к увеличению переохлаждения под фронтом кристаллизации, что увеличивает вероятность образования дендритной структуры. Связь параметра $G_{L} / V$ с образованием дендритной структуры наблюдалась во многих процессах кристаллизации. Например, в работе [18] для получения кристаллов ферромагнитного сплава $\mathrm{Co}_{37} \mathrm{Ni}_{34} \mathrm{Al}_{29}$ использовался метод направленной кристаллизации с высоким градиентом температуры. Наличие или отсутствие дендритов в выращенных кристаллах связывалось с величиной параметра $G_{L} / V$. С подобными проблемами образования дендритов в структуре отливок сталкивались разработчики жаропрочных никелевых сплавов. В данном случае для получения заготовок турбинных лопаток применялся метод направленной кристаллизации $[24,25]$. Результаты этих работ и наши данные приведены в табл. 2.

Из приведенных данных видно, что образование дендритов при кристаллизации коррелирует с параметром $G_{L} / V$. Для исключения образования дендритов необходимо увеличивать градиент температуры на фронте кристаллизации и уменьшать скорость роста.

\section{2. Изменения элементного состава дендритов}

Полученные результаты по химическому составу дендритов согласуются с известными ранее данными по дендритам в сталях [22]. Для многокомпонентных сталей было показано, что дендриты обогащены наиболее тугоплавким компонентом. В нашем случае для состава $\mathrm{Ni}_{49} \mathrm{Fe}_{18} \mathrm{Ga}_{27} \mathrm{Co}_{6}$ таким компонентом является железо (темература плавления $1539^{\circ} \mathrm{C}$ ).

Изменение элементного состава дендритов наблюдалось также и при кристаллизации других сплавов с ЭПФ. Например, в [21] элементное картирование с помощью электронного сканирующего микроскопа в сплаве $\mathrm{Ni}_{52} \mathrm{Fe}_{20} \mathrm{Ga}_{26} \mathrm{Co}_{2}$ выявило в дендрите увеличение содержания железа и кобальта и уменьшение содержания галлия по сравнению с окружающей матрицей. Подобный результат по изменению содержания этих элементов получен и в [16].

\section{3. Влияние дендритной структуры на мартенситные переходы}

Несомненный интерес представляет обнаруженный в ходе наших исследований эффект остановки мартенситных игл на дендритах. В соединениях типа $\mathrm{NiFeGaCo} \mathrm{в} \mathrm{аустенитном} \mathrm{состоянии} \mathrm{основная} \mathrm{фаза} \mathrm{имеет}$ ОЦК-решетку $L 2_{1}$ и описанную во многих работах неупорядоченную $\gamma$-фазу (или дендриты), имеющую ГЦК-решетку [17]. При фазовом превращении аустенит $\rightarrow$ мартенсит основная фаза переходит в гранецентрированную тетрагональную решетку мартенсита $L 1_{0}$, тогда как в $\gamma$-фазе сохраняется ГЦК-решетка [26]. Кроме того, как показали наши измерения, дендрит имеет отличный от матрицы элементный состав, в котором сильно смещена температура мартенситного превращения, либо оно не имеет места. Фактически, это инородное включение в матрице кристалла $\mathrm{NiFeGaCo}$, полностью блокирующее или затрудняющее движение мартенситных кристаллов. При наличии дендритов не весь объем кристалла участвует в мартенситном превращении. При очень высокой плотности дендритов, как например, на образце вблизи затравки (рис. 2, $a, d$ ) области между отдельными дендритами могут быть меньше критических, необходимых для перестройки решетки в мартенситную фазу [27].

\section{5. Выводы}

1. Способом Степанова из расплава выращены длинные профилированные кристаллы $\mathrm{Ni}_{49} \mathrm{Fe}_{18} \mathrm{Ga}_{27} \mathrm{Co}_{6}$ диаметром 6 и длиной до $250 \mathrm{~mm}$ с эффектом памяти формы.

2. Показано, что неоднородность структуры по длине и поперечным сечениям этих кристаллов главным образом связана с дендритной структурой, образующейся на фронте кристаллизации.

3. Химический состав дендритов отличен от состава матрицы кристалла, содержание железа в дендрите приблизительно на $30 \%$ больше, а содержание галлия приблизительно на 40\% меньше и находится в области составов, где не наблюдается ЭПФ. 
4. Показано, что дендриты, кроме того, являются препятствиями для прорастания мартенситных кристаллитов в матрице $\mathrm{Ni}_{49} \mathrm{Fe}_{18} \mathrm{Ga}_{27} \mathrm{Co}_{6}$ при мартенситных превращениях в термоциклах.

5. Моделирование процесса кристаллизации этих кристаллов способом Степанова указывает, что для подавления образования дендритов и получения бездендритных кристаллов необходимо изменить конструкцию ростовой зоны, так, чтобы увеличить градиент температуры на фронте кристаллизации и при этом снизить скорость вытягивания кристаллов.

\section{Благодарности}

Авторы благодарят С.А. Пульнева за помощь в работе на установке и полезные обсуждения.

\section{Конфликт интересов}

Авторы заявляют, что у них нет конфликта интересов.

\section{Список литературы}

[1] Heusler Alloys, Properties, Growth, Applications / Ed. C. Felser, A. Hirohata, Springer International Publishing, Switzerland (2016). 486 p.

[2] В.Д. Бучельников, А.Н. Васильев, В.В. Коледов, С.В. Таскаев, В.В. Ховайло, В.Г. Шавров. УФН 176, 8, 900 (2006).

[3] V.I. Nikolaev, S.I. Stepanov, P.N. Yakushev, V.M. Krymov, S.B. Kustov. Intermetallics 119, 1 (2020).

[4] E.Yu. Panchenko, E.E. Timofeeva, N.G. Larchenkova, Yu.I. Chumlyakov, A.I. Tagiltsev, H.J. Maier, G. Gerstein. Mater. Sci. Eng. A 706, 95 (2017).

[5] В.И. Николаев, П.Н. Якушев, Г.А. Малыгин, С.А. Пульнев. ПЖТФ 36, 19, 83 (2010).

[6] R.F. Hamilton, H. Sehitogly, C. Efstathiou, H.J. Maier. Acta Mater. 55, 4867 (2007).

[7] J. Jani, M. Leary, A. Subic. J. Intell. Mater. Syst. Struct. 28, 13, 1699 (2017).

[8] С.А. Пульнев, А.И. Прядко, С.Г. Ястребов, В.И. Николаев. ЖТФ 88, 6, 843 (2018).

[9] А.И. Прядко, А.В. Чикиряка, С.А. Пульнев. ЖТФ 89, 12 , 1880 (2019).

[10] J.K. Kearns. Silicon single crystals. In: Single Crystals of Electronic Materials Growth and Properties / Ed. R. Fornari. Elsevier Ltd (2019). P. 5.

[11] P.I. Antonov, V.N. Kurlov. Prog. Cryst. Growth Charact. Mater. 44, 63 (2002).

[12] А.И. Аверкин, В.М. Крымов, Л.И. Гузилова, Р.Б. Тимашов, А.В. Солдатов, В.И. Николаев. ПЖТФ 44, 3 (2018).

[13] Ю.Г. Носов, А.В. Солдатов, В.М. Крымов, С.А. Пульнев, В.И. Николаев. ПЖТФ 45, 2729 (2019).

[14] Г.А. Малыгин, В.И. Николаев, В.М. Крымов, С.А. Пульнев, С.И. Степанов. ЖТФ 89, 873 (2019).

[15] S. Belyaev, N. Resnina, V.I. Nikolaev, R.B. Timashov, A. Savelieva, A. Gazizullina, V.M. Krymov, A. Sibirev. J. Mater. Eng. Perform. 28, 7, 4234 (1918).

[16] K. Oikawa, T. Omori, Y. Sutou, H. Morito, R. Kainuma, K. Ishida. Met. Mater. Trans. A 38, 767 (2007).
[17] J. Liu, N. Scheerbaum, D. Hinz, O. Gutfleisch. Acta Mater. 56, 3177 (2008).

[18] J.Z. Li, B. Huang, J.G. Li. J. Cryst. Growth 317, 110 (2011).

[19] Q. Liu, J. Liu, Y. Huang, Q. Hua, J. Li. J. Alloys Compd. 572, 186 (2013).

[20] P. Jiang, J. Bai, P. Wei, S. Han, M. Yang, F. Teng, X. Wang, X. Zhao. Mater. Sci. Forum 879, 2061 (2017).

[21] G. Gurau, C. Gurau, F. Tolea, V. Sampath. Materials 12, 1939, 1 (2019).

[22] И.Н. Голиков, С.Б. Масленков. Дендритная ликвация в сталях и сплавах. Металлургия, М. (1977).

[23] B. Chalmers. Principles of Solidification. John Wiley, N.Y. (1964). 319 p.

[24] Е.Н. Каблов, В.Н. Толорайя, И.М. Демонис, Н.Г. Орехов. Технология легких сплавов 2, 60 (2007).

[25] Е.М. Висик, В.В. Герасимов, Е.В. Колядов, Е.В. Филонова. Завод. лаборатория. Диагностика материалов. 84, 6, 38 (2018).

[26] K. Oikawa, T. Ota, Y. Sutou, T. Ohmori, R. Kainuma, K. Ishida. Mater. Transact. 43, 9, 2360 (2002).

[27] Г.А. Малыгин. ФТТ 61, 7, 1310 (2019).

Редактор Е.Ю. Флегонтова 